\title{
La imagen de lo femenino. La estatuilla antropomorfa de la Capacocha del cerro El Plomo
}

\section{The feminine image: the anthropomorphic figurine at the Cerro El Plomo capacocha site}

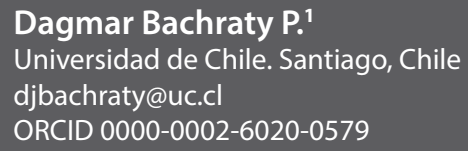

Citar como: Bachraty, D. (2019). La imagen de lo femenino. La estatuilla antropomorfa de la Capacocha del cerro El Plomo. Desde el Sur, 11(2), pp. 317-329.

\section{RESUMEN}

La Capacocha del cerro El Plomo tuvo lugar en la cima del apu ubicado en el valle del Mapocho, actual Santiago de Chile. Al respecto, se sostiene que tan importante ritual incaico no solo significó una ceremonia de carácter político-religioso dentro de los valles conquistados, sino, además, un mecanismo de eficacia simbólica como medio de introducción ideológica o andinización de las etnias locales existentes en el valle.

Por ello, la utilización de estatuillas antropomorfas dentro del ritual, como la encontrada en 1954 bajo el contexto de huaqueo del sitio arqueológico, pone en evidencia la estandarización de la materialidad simbólica dentro del Incario, pero también distintiva identitariamente hablando, debido al diseño estético del textil. Debido a esta premisa, se cree importante el análisis semiótico bajo un acercamiento desde el mito fundante inca como estrategia política y social de orden, pero también simbólica respecto del espacio.

\footnotetext{
1 Licenciada en Historia, magíster en Estéticas Americanas de la Pontificia Universidad Católica de Chile, y doctoranda en Estudios Latinoamericanos de la Universidad de Chile (Beca Conicyt). Dentro de sus áreas de interés académico destacan las líneas de investigación etnohistóricas, antropológicas y estéticas, centrados en la simbología de los textiles y su utilización ritual, a través del estudio de la cosmología, la política y la economías andinas, principalmente del Tawantinsuyu. Actualmente, investiga la Capacocha del cerro El Plomo y el paso del Inka por el valle del Mapocho (Santiago de Chile).
} 


\section{PALABRAS CLAVE}

Capacocha de El Plomo, figura antropomorfa femenina, simbolismo, textiles

\section{ABSTRACT}

The Cerro El Plomo capacocha ceremony occurred at the top of a sacred peak, or Apu, situated in the Mapocho Valley, where Santiago de Chile is now located. Archaeologists believe that such an important Inca ritual was not only of a political-religious nature within the conquest of conquered valleys, but that it also functioned as a mechanism of symbolic efficacy, and as a means of achieving the ideological introduction and assimilation of the local ethnic groups that had occupied the valley before the arrival of the Incas.

The use of anthropomorphic figurines as part of the ritual, like the one found in 1954 in the context of an invasion of an archaeological site by tomb robbers, highlights the standardization of symbolic material within the Inca state, as well as the distinctive identity components apparent in the design of textiles. In light of these factors, a semiotic analysis is required, based upon interpretation of the Inca foundation myth as a political and social strategy, as well as that same myth's symbolic spatial components.

\section{KEYWORDS}

Cerro El Plomo capacocha, female anthropomorphic figurine, symbolism, textiles

\section{Introducción}

A partir de una variada evidencia arqueológica concerniente a la presencia del Tawantinsuyu en los valles centrales de Chile, más específicamente en el valle del Mapocho, se inició un estudio multidisciplinario desde la arqueología, la antropología y la etnohistoria, respecto del potencial simbólico presente en dicho material. Este estudio podría llegar a dilucidar la importancia ideológica dentro de los procesos de andinización de las etnias locales dentro de dicho valle, así como proyectar el carácter político del Incario dentro de zonas tan meridionales del Tawantinsuyu, vista a través del aspecto estético de los textiles.

El siguiente artículo tiene por objetivo destacar la importancia del textil como recurso estético y social respecto del rol simbólico de la mujer en rituales de la envergadura de la Capacocha. Por este motivo, la referencia 
de lo femenino, presente en la estatuilla antropomorfa del ajuar de la Capacocha de El Plomo, nos puede acercar a la reconstrucción de dicha imagen a través del análisis del textil y el lenguaje presente en sus colores.

El pensamiento andino, que interrelacionaba la vida, la muerte, la sociedad, la historia o sus creencias, estaba ligado a una compleja red simbólica entrelazada con un todo cósmico. Este pensamiento establecería una cohesión social como orden político, el cual creemos se encuentra representado en la producción de objetos como textiles, cerámicas o figurillas hechas en metal. Estos objetos tornaban en significación si efectivamente representaban una realidad, un algo que debía ser contado, perpetuado y refigurado mediante la relación con una materialidad sagrada, un mito y su rito. Este objeto, como portador de memoria e identidad, materializaba una historia común basada en un orden aceptado comunitariamente debido a la hegemonía de un poder cultural; en este caso, el incaico.

Los artefactos - las figuritas antropomorfas - necesitaron de otro objeto para reafirmar su poder mágico-ritual. Esta dualidad existente en el mundo andino, tras la idea de los opuestos complementarios, es visible, por ejemplo, en el mito de los hermanos Ayar. Al salir de la cueva en pares masculino-femenino, los hermanos Ayar estructuraron un pensamiento binario como forma de entender y ordenar el mundo que los rodeaba. De igual manera, los objetos que los acompañaron en el mito nos hablan de una representación material del mundo cosmológico a través de una relación hombre-objeto y, por ende, hombre-mujer.

Es así como las estatuillas antropomorfas encontradas en contextos arqueológicos de rituales de altura, como la Capacocha, nos hablarían de un orden social binario establecido a través de un pensamiento complementario. Si bien el poder político era masculino, la herencia de dicho poder habría correspondido, según estudios realizados por María Rostworowski (2017), a la panaca de la kolla. Por lo tanto, la conservación del poder o la lucha por el poder como herencia política (sanguínea) se habría dado de forma matrilineal, a través de lazos políticos establecidos mediante las relaciones matrimoniales. Asimismo, este orden es observado en la conformación de ofrendas de altura, donde la imagen femenina de los objetos constituiría una imagen de la realidad, es decir, la de un «objeto social total» (Augé, 1988), como representación política, social y espiritual.

La imagen de la figura antropomorfa femenina encontrada en contextos de la Capacocha del cerro El Plomo (1954) correspondería a una imagen asociada a la kolla, debido al análisis textil. El estudio de los diseños y los colores de su vestimenta nos hablarían de una imagen vinculada no solo a una élite, sino a un poder asociado a la fertilidad. En este sentido, el símbolo de la doble serpiente (amaru), existente en la imagen geométrica 
(asociado, además, al vestuario del inka) de la faja del vestido, estaría vinculado, gracias a la presencia de un símbolo escalonado similar al de la chakana y al tocapu, a una representación de orden político y cultural.

Desde esta lectura simbólica, el color rojo preeminente en el textil de la estatuilla podría asociarse al significado sagrado de la mujer como productora cultural y biológica, puesto que, como revisaremos, el rojo (en alusión a la sangre menstrual) se vincularía, más allá del carácter propiciatorio del ritual, al poder desde donde emanaba, es decir, al rol político de la kolla. En este aspecto, el cronista Garcilaso de la Vega nos ha dejado una inquietud en cuanto al rol de la mujer y su configuración social, puesto que «las mujeres por su calidad eran de la misma sangre del sol, por todos estos respectos las tenían en suma veneración» $(1609$, p. 209).

\section{La importancia del color y el textil en el Incario}

Como señala Garcilaso de la Vega (1609), el arte de la textilería correspondía en el mundo incaico a una tarea relacionada principalmente con las mujeres. Las mejores y más hábiles tejedoras debían tributar para el Cusco tanto mantas como túnicas de diversa confección, que se dividían, según su empleo, para el uso doméstico y la destinada para la nobleza y sus gobernantes. Las mujeres dedicadas a la confección textil de la nobleza eran llamadas «mujeres del Sol» y estaban recluidas en un acllahuasi («casa de las escogidas»). Con ello, cumplían una función sagrada, debido a la delicadeza de su trabajo y también al rol memorístico de este tipo de prendas.

Aquellas cosas eran hechas por las manos de las coyas (mujeres del Sol) y hechas para el Sol, y las mujeres por su calidad eran de la misma sangre del Sol, por todos estos respectos las tenían en suma veneración. Y así el mismo inca no podía darlas a otro alguno que no fuese de su sangre real y parentela, porque las cosas divinas - decían ellos- no era sino sacrílego emplearlas en hombres humanos. Y de aquí le era prohibido al mismo rey dar a los curacas y capitanes, por mucho que hubiesen servido, si no fuesen de su sangre (Garcilaso, 1991 [1609], p. 209).

De esta manera, y como sostiene Garcilaso, podemos inferir que tanto la mujer, en su calidad de productora social, cultural y sagrada, puede ser ligada con la presencia del color rojo asociado a la sangre (menstrual), como símbolo de fertilidad y también de relación política o parentesco. Asimismo, estaban reservadas solo para hombres de un linaje real y no a cargos de ascensos político-militares. Por otra parte, en su rol de tejedoras, estas mujeres pasaban a cumplir un rol valioso para el Incario, debido al papel importante dentro de la transmisión nemotécnica de la historia inca y, por lo tanto, política. Este aspecto no implicaría un poder en sí mismo, puesto que, como todo sistema político, el Incario debió ejercer un 
fuerte control dentro de su producción simbólica. Sin embargo, son mujeres «escogidas» las que hilvanan y conocen a fondo la complejidad de la estructura comunicacional andina.

Esta matriz podría tener su significado y origen en los albores del tejido en el mundo de los Andes. Este, en el mundo incaico, correspondería a un arte ancestral basado en el mito de Mama Ocllo, según el cual «ella enseñó el arte de unir los hilos a las mujeres, prodigándoles un soporte de memoria. En muchas culturas, el tejido se vincula con diosas hilanderas, con el poder sobre el destino, y el ritmo de la vida y la muerte que caracterizan a la existencia dentro del tiempo» (Corcuera, 1987, p. 57). Podemos agregar al respecto que la acción de tejer no solo correspondería a un arte de contar y preservar sus tradiciones, sino a un mundo femenino vinculado a un contexto estatal del Tawantinsuyu. Como señala Garcilaso de la Vega, las tejedoras más virtuosas de cada provincia estaban destinadas a vivir en el Cusco, y quedaban a disposición del inka y su corte. Este control político sobre la memoria del textil es un aspecto que debe ser considerado cuando se evalúa la predominancia de un símbolo por sobre otro. $Y$ con ello, lo que se desea contar y preservar como texto de dominio.

Según Ruth Corcuera (1987), el virtuosismo es uno de los componentes que colocan al tejido dentro del fenómeno de lo creación artística, y establece siempre un punto de encuentro entre el hombre y el Universo, tal cual la tejedora lo interpreta. «El tejido sagrado llevaba mensajes simbólicos, mitogramas, mensajes que acompañando al ajuar funerario iban a establecer un diálogo con los dioses en un tiempo no atado a lo humano» (Corcuera, 1987, p. 58). Debido a esto, es posible inferir que los textiles corresponden a imágenes de un mundo en directa relación con los fenómenos naturales y sus divinidades. Es así como las civilizaciones andinas, observadoras de su medio ambiente, desarrollarían un pensamiento que se concentraba en el tema de la fertilidad, a causa de la dependencia del clima y el factor agua. $Y$ con ello a los ciclos vitales.

Retomando la estética del textil en el mundo incaico, este, en su complejidad y diversidad en cuanto a forma de expresión cultural, corresponde a una red de signos que incluían la utilización del color como un símbolo en sí mismo. Los signos eran reconocidos por una comunidad y establecían un lenguaje que representaba no solo su entorno, sino también su mitología. Se entregaba con ello un mensaje visual referente a toda su cultura e historia.

Esta conceptualización manifestada bajo un discurso cromático tiene como ejemplo el contexto cultural y político de una hegemonía basada en la representación y el diseño de un poder político. 
Los famosos uncu (con tocapus) realmente se pueden asociar con los incas o con el Sapa Inca, cuyo conjunto de tocapus prácticamente representaba el imperio. Los incas manipularon esta codificación de tal modo que determinaron quiénes y qué etnias podían llevar qué tipo de vestido y de qué color, con lo cual se puede hablar de un control de la codificación del color (Brugnoli, 2011).

Asimismo, el uso de los colores recaía no solo en su aplicación ritual o simbólica, sino que, además, era transmisora del poder desde donde emanaban. Para Gabriela Siracusano (2005), la materialidad en el mundo andino — como pigmentos, colores, piedras, cerros o aguas del paisajeescondían la marca de lo poderoso, en donde la geografía sagrada sería la portadora de la memoria de los ancestros. Entonces, la confección de objetos especiales para la celebración de rituales como la Capacocha deberían manifestar y portar aquel poder presente en el objeto.

En este sentido, el rojo utilizado ritualmente correspondería a un arbusto denominado con la palabra ichma, similar a Ychsm. Este aspecto podría corresponder a una vinculación política y simbólica asociada el templo de Pachacamac, debido a la existencia de dicha planta en ese lugar. En el idioma de la gente de la costa peruana o yunga, Pachacamac correspondería a un vocablo compuesto de origen quechua (runasimi), adoptado por los incas, y que significa el «hacedor del mundo». Según el cronista Antonio de la Calancha (1638), ishma era sinónimo de Ilimpi, nombre aplicado al azogue y a su color bermellón, utilizado como maquillaje en diversos rituales. Este color se habría obtenido del fruto de un arbusto llamado ichma y el llimpi, de origen mineral. Bajo esta perspectiva, el cronista sostiene la existencia de un vínculo entre los materiales y una espiritualidad, puesto que aseguraba que los indígenas los adoraban besándolos y soplándolos:

Paria es polvos de color colorado, como de bermellón, que traen de las minas de Huancavelica, que es el metal de que se saca el azogue, aunque más parece a zarcon. [...] Usavan los indios que van a minas de plata, de oro o de azogue, adorar los cerros o minas, pidiéndoles metal rico, i para esto velan de noche, beviendo i baylando, sacrificio que azen a la riqueza; a los de oro llaman Coya, i al Dios de las minas de plata i a sus metales Mama, i a las piedras de los metales Corpa, adóranlas besando, i lo mesmo al soroche, al azogue i al bermellón del azogue, que llaman Ichma, o Linpi, i es muy preciado para diversas supersticiones (Calancha, 1638, pp. 371-372).

Igualmente, Bernabé Cobo describe al Ilimpi y su importancia como un color obtenido del metal del azogue, donde en conjunto con otros colores simbolizaba la tierra en diferentes fiestas y celebraciones (Boletín MNHN, 1957-1959, p. 32). Por lo mismo, este color de gran importancia ritual tendría un vínculo directo con la huaca y su correspondencia con lo sagrado. 
Bajo este sentido sacro en cuanto a la denominación y materialidad a la cual representaba al color en el mundo andino, el rojo corresponde al color más visible en el contexto de la Capacocha de El Plomo. El uso cromático del color podría señalar una vinculación con su entorno y forma de entender el mundo, bajo la presencia de una policromía asignada a una simbología propia de su cultura y espacio político. La importancia de la visualidad y la presencia de luz en los colores incaicos denotan un rasgo característico que generarían lazos identitarios políticos en sus ritos y mitos. Por ello, el rojo denotaría la presencia de la tierra, su fuerza y vitalidad asociada a la sacralidad y tiempo a través del entendimiento e importancia de lo que prodigaba la Pachamama. En este sentido la Pachamama debe entenderse en un sentido global, que incluye a la tierra y sus dones, así como a la naturaleza en su conjunto y tiempo. Para Paulina Brugnoli (2011), este aspecto del tiempo y la naturaleza estaría asociado a la importancia mítica del color en los Andes y a la primera humanidad, en donde esta habría vivido en las penumbras (cuevas / mito hermanos Ayar / tiempo primigenio), hasta la creación de la luz/sol llevada a cabo por Wiracocha. La luz y la sombra, o el ser y nacer, serían representado en textiles de distintas culturas serranas como ambientes uterinos (Brugnoli, 2011).

Por otra parte, la Pachamama, como tiempo primordial asociado a lo femenino, podría ser la clave para la comprensión desde donde emanaba el poder del color rojo y su importancia ritual y política, puesto que no ha de olvidarse que la borla de poder llamada mascaypacha era siempre de color rojo, como sostienen diversos cronistas. En este sentido, María Rostworowski postula que el rol político de la mujer de la élite tenía directa relación con el carácter hereditario del poder de la panaca de su procedencia. Es decir, la panaca de la kolla tenía privilegio frente al Consejo Real en la elección del hijo «más hábil» (Rostworowski, 2017, p. 107). Este aspecto sería tergiversado por los cronistas, al presentar las sucesiones como tradiciones patrilineales, debido a su propia concepción europea del poder político.

Desde el punto de vista social, la mujer también estaba estratificada respecto de su origen y función. La kolla, en su concepción de reina y pariente del Sol, poseía un sequito de sirvientas equivalente a los yanas. Las niñas de entre 8 y 10 años, elegidas para formar parte de los acllahuasi bajo el título de mamaconas, eran las encargadas de confeccionar los textiles y los brebajes para las fiestas y ceremonias (Rostworowski, 2005, p. 100). Asimismo, se clasificaban respecto de su linaje: mientras más cercano era el linaje al inka, se desempeñaban como sacerdotisas de Inti y oficiaban en los templos. Por lo mismo, no ha de olvidarse que las niñas escogidas para la Capacocha tenían entre 8 y 15 años, aproximadamente. Ellas cumplirían un rol simbólico y, además, sellarían pactos políticos entre el Cusco y las provincias anexadas. 


\section{Desde la antropología histórica: análisis material de la figurilla femenina}

Para Marc Augé, los objetos constituyen el soporte del símbolo y del fetiche; la cosa propiamente dicha, que puede ser de distintas clases: natural como un trozo de madera, piedra, metal o elementos de la naturaleza dotados de una unidad propia que facilita su personalización; un objeto fabricado que asocia varias materialidades; $y$ un objeto tratado desde una materialidad viva (1988, p. 30). Curiosamente la Capacocha conjuga estos tres tipos de objetos. El culto, entonces, «no es pues, según parece, la idolatría grosera de un objeto material. El fetiche es la morada donde reside el espíritu» (Augé, 1988, p. 22). Con ello se alude a su componente performativo presente en el poder material de la figura.

El objeto material representa a una cultura, cuando esta lo ha dotado de significado, es decir, le ha otorgado un símbolo con un valor operativo y una acción social. Este nexo entre objeto y la idea que lo hace existir no constituiría simplemente una relación social, sino que correspondería también a un esfera del ser, puesto que la identidad y la materialidad que la representa se encuentra en todo dispositivo simbólico (Augé, 1988, pp. 138-140).

Los objetos que se han encontrado en diferentes Capacochas a lo largo de los Andes han sido sometidos a diversas interpretaciones. La similitud casi exacta en el tipo de objetos hallados junto a los niños del Llullaillaco y de El Plomo hacen creer que este ritual estaba ordenado bajo un estricto control cusqueño. Las interpretaciones de dichas ofrendas recaen justamente en una significación asociada a la política del Incanato y otra referente al ámbito religioso-cultural.

La primera de estas visiones entiende que los objetos en miniatura representan el universo social de los adultos, el cosmos del inka, sus súbditos, sus posesiones y sus anhelos expansivos, o bien constituyen una imagen de las clases sociales y las jerarquías del Tawantinsuyu. La segunda interpretación sostiene que las miniaturas estarían rodeadas de una voluntad propiciatoria, por ser ellas la «esencia vital de los rebaños», un medio para obtener «riqueza» $y$ «ventura». Ambos aspectos son referenciados por Pablo Mignone (2015), tomando como base fuentes etnohistóricas o experiencias etnográficas, como la de Jorge Flores Ochoa (1977), quien estudió comunidades pastoriles en Cusco y Puno para analizar el uso de miniaturas de camélidos. Este estudio habría reafirmado la importancia propiciatoria, debido a su relación con los componentes del espacio ceremonial (Mignone, 2015).

La figura femenina antropomorfa del ajuar perteneciente al Niño de El Plomo, en contextos del ritual llamado Capacocha, fue encontrado por huaqueros en las cercanías del adoratorio de altura existente en la cumbre 
de dicho cerro. Este hallazgo arqueológico sucedido en 1954 corresponde a un descubrimiento parcial, puesto que el adoratorio ya había sido hurgado desde finales del siglo XIX y comienzos del siglo XX.

La figura encontrada junto con otros objetos como una chuspa, bolsita de plumas blancas y rojas rellena de hojas de coca, tres saquitos de escroto de llama en cuyo contenido había pelo, dientes y uñas del niño (unidas con un hilo rojo), figuritas zoomorfas de oro y spondylus, y el ajuar textil propio del único niño encontrado dentro de este contexto.

El textil visto como un indicador valórico de prestigio social nos habla de la Capacocha de El Plomo y otros rituales, de una ofrenda, es decir, de un lenguaje transversal, si lo comparamos con otros rituales de altura, como el de Llullaillaco. Claramente existe una distinción social e identitaria respecto al uso de los textiles y la importancia de la urdiembre, diseño y color.

La figura femenina en cuestión es de plata, de unos $15 \mathrm{~cm}$, con un peinado hecho con una partidura al medio de la cabeza y trenzas que cuelgan por su espalda amarradas con algún tipo de atavío. Corresponde a una sola pieza, trabajada tal vez mediante un molde, y se visualizan uniones o terminaciones a modo de cordón entre las piernas, pero no así en sus costados. En su cabeza se aprecian dos hendiduras, una en la zona de la mollera y otra en el costado izquierdo. Posee pies planos, lo que le permitiría sostenerse en pie. Su sexo se encuentra bien definido, y sus brazos están flectados hacia el pecho, tapando ambos senos. Se trata de una posición simbólica, que bajo nuestra interpretación se aproximaría a un efecto performativo vinculado a la reciprocidad andina.

El símbolo de la materialidad de la plata con la que está hecha la estatuilla es múltiple dentro de su análisis. Este material, al igual que la materialidad desde donde emana el color rojo (la tierra), también aludiría a un ámbito simbólico de lo femenino. Para Rob Morssink (1999), este simbolismo representa a la Luna, a la Pachamama, a aguas quietas de lagos y océanos, a agua de fuentes y a lo concerniente con lo femenino relativo a los dioses y ancestros como forma de ofrenda (Morssink, 1999, pp. 49-50). Singularmente, todos estos espacios acuíferos representan lugares relativos a la celebración de la Capacocha.

Cabe destacar que estatuillas del tipo femenino también están presentes, como ha sido mencionado, dentro el ajuar de los niños encontrados en el volcán Llullaillaco, en Salta (Argentina). En esos casos, la diferenciación corresponde a la vestimenta, por lo que podría desprenderse de ello una distinción étnica dentro del territorio conocido como Collasuyu. Además, en el Museo de Antropología e Historia de Lima se encuentra una estatuilla casi idéntica de aleación oro y plata, pero de un tamaño mucho mayor, sin vestimenta, y referenciada en el Horizonte Tardío, al igual que las otras estatuillas. 
Respecto de su descripción etnográfica, el vestido o anaku de la estatuilla del cerro El Plomo es de color café, con franjas de café más claro, rematada en sus bordes con hilo de tonalidad similar. Posee un orden geométrico al estilo incaico en torno a la confección de rectángulos, separados por dos franjas de café oscuro en sus bordes, con dos grupos de líneas de tres corridas de color café oscuro al centro (tipo talega).

La manta o lliclla superior está compuesta por un tejido de urdiembre similar, con un diseño geométrico separado por tres áreas; en sus costados de un color café y en el centro café claro, separados por finas franjas rojas y amarillas. Los bordes están rematados por hilos que van alternándose de amarillo, rojo, amarillo y verde, y repiten la secuencia. Cabe agregar que el amarillo y el rojo fueron pigmentos encontrados en la pintura facial del Niño de El Plomo.

Los textiles van amarrados a la cintura por una faja o cinto, con dibujos geométricos que pueden hacer referencia a la serpiente de dos cabezas (de rojo) y unos cuadrados (de azul) al centro, que se asemejan al cosmograma del mundo andino presente en la chakana. La faja presenta colores, azul en sus bordes, y amarillo y rojo en su centro. Desde uno de sus extremos sobresale un trenzado de hilo azul y rojo, el cual termina en una borla de lana de ambos colores.

La vestimenta es complementada con un pequeño cordón, cuyo color predominante es el rojo granate. Está compuesto por un cordón principal trenzado rojo, amarillo y azul, en donde se distinguen dibujos ordenados geométricamente con rombos en su interior y líneas que asemejan a una serpiente. De su centro cuelgan dos trenzas que terminan en dos rectángulos de concha del tipo spondylus por su color rojizo. En los costados hay dos amarras con tupus, para el cierre de la prenda.

La figura antropomorfa es vestida con la manta café, amarrada con la faja (la cual no se ve), recubierta por la manta de bordes coloridos ataviada por el cuello con el cinto o cordón con placas de spondylus al centro y cerrada por los tupus.

El atuendo se complementa con un tocado de plumas rojas, hiladas a un material del tipo arpillera. De su parte posterior sobresale un segmento que cubre la nuca y parte de la espalda. Esta parte no está recubierta por plumas, pero posee un dibujo geométrico en su parte inferior con hilos rojizos. Además, posee una amarra en su parte delantera, que se ajusta a la zona de la barbilla.

Como conclusión analítica es posible referenciar que:

1. La vestimenta de la figura femenina presenta un urdiembre y tejido de mayor calidad que la vestimenta del niño ofrendado en El Plomo. Su urdiembre y diseño corresponden a la de un atuendo de uso cotidiano 
y no ritual (por su calidad y confección, si lo comparamos con los atuendos de otros niños ofrendados). Ello tal vez se deba a que esta estatuilla representa a una mujer de la élite cusqueña, debido al colorido y manufactura de sus prendas, y la del niño a un contexto inca local.

2. Presenta una serie de símbolos característicos de un ritual de fertilidad, como la serpiente de doble cabeza o el esbozo de una chakana, además de la importancia predominante del color rojo y color tierra en los textiles. Este aspecto haría aludir a los ambientes uterinos mencionados por Brugnoli.

3. La manta de la vestimenta presenta una terminación de hilados de colores, tal vez referentes de algún tipo de código lingüístico o social. John Murra destaca la relevancia del tejido en contextos rituales religiosos, identitarios, sociales y económicos.

4. El tocado como parte de la vestimenta, el plumaje y el color nos hablan de una jerarquía importante dentro del contexto social que representa la estatuilla. Para el mundo incaico, la materialidad hace presente la manifestación de la deidad o de los ancestros. El rojo hace alusión a lo vital, a lo femenino y a los ciclos de reproducción natural.

\section{Conclusiones generales}

En contextos generales es posible concluir que existe, gracias al análisis textil de estatuillas referentes a contextos rituales, una importancia distintiva respecto al diseño y colorido de las prendas, lo que aludiría a un rango simbólico de su posición social. Este mismo espectro simbólico referido al uso del rojo no solo podría referenciar un significado respecto a la fertilidad o la idea cíclica de la vida, sino un carácter político que emanaría desde el ámbito de los opuestos complementarios y su representación mítica a través del relato de los hermanos Ayar como héroes civilizatorios. En este sentido, el rojo, asociado a la idea de tiempo y espacio como germinador primigenio, contextualiza la importancia ritual y política de lo femenino, impreso a través de los textiles como portadores visibles de su historia. Más allá de la característica femenina de la confección del textil, las prendas relacionadas con aspectos políticos y rituales llevaban impresos mitogramas (tocapus), con un claro sello que alude a la importancia del ciclo de la naturaleza.

Al mismo tiempo, si observamos otros unkus del tipo incaico y su diseño geométrico, es posible contrastarlos con el símbolo similar al de la serpiente de dos cabezas existentes dentro de la prenda femenina de la estatuilla. Este aspecto facilitaría la comprensión del significado político y simbólico de la mujer, aludiendo a que la representación de la serpiente o amaru también corresponde a un ámbito sagrado referente a la movilidad y resurrección de los ciclos vitales, pero además a un poder político emanado desde su génesis cosmológica. Asimismo, los textiles dentro de su concepción mítica aludirían a un espectro comunicacional transmitido desde Mama Ocllo, en el cual la 
mujer jugaría un rol importante dentro de la concepción de la memoria y su transmisión. Por ello, dentro de la ritualidad de la Capacocha los textiles como ofrendas llevarían impresos mitogramas como forma de comunicación con los dioses y ancestros que estructuraron su mundo. Existe con ello un vínculo de reciprocidad y de espejo entre un lado y otro. Un mundo basado en la idea de complementación de los opuestos complementarios, en donde la mujer perteneciente a las élites cusqueñas jugaría un rol primordial en el momento de colocar a su hijo, él «más hábil», en la cúspide del poder.

Dentro del contexto Capacocha, estos textiles nos hablan de un rol político y lingüístico de la sociedad incaica. Este ritual del tipo propiciatorio, efectuado en lugares de generación de agua, estaría directamente vinculado con la concepción cosmológica de lo femenino, en directa alusión al estado de renovación y presencia política del Incario bajo ámbitos de reciprocidad en la generación de recursos del tipo agrario.

Esta característica del hombre serrano, como ente observador de los ciclos productivos de la naturaleza y la mujer, se relacionó a una producción mitológica desarrollada a través de objetos textiles, cerámicos y estatuillas metalúrgicas, los cuales plasmaron el componente oral/ideográfico como sustento nemotécnico de su historia. Estos objetos con particularidades performativas fueron utilizados para generar un vínculo propiciatorio en los valles, el cual reafirmaría el poder político a través de la restitución del mito originario. En este sentido, el útero y su significado como huevo cosmogónico primigenio corresponderían a una semilla de germinación en directa relación con su producción mítica y materialidad (lugar y composición desde donde se extrae la materia prima: la tierra/Kay Pacha), puesto que de sus características fertilizadoras se extraería la noción tempore espacial cíclica del concepto de la Pachamama. Sin embargo, se observa que el mundo andino, dentro de sus orígenes y relatos míticos, surge de la mano de dioses masculinos, los cuales, a través de una simbología gestacional del huevo (matriz/ovogénesis), darían paso al acto creador, en conjunción con la acción femenina de la Pachamama.

\section{Contribuciones}

Contribución completa de Dagmar Bachraty.

\section{Fuente de financiamiento}

Investigación financiada por Conicyt. La autora es beneficiaria de una beca de doctorado.

\section{Conflicto de intereses}

No existe. La autora no es parte de la institución responsable de la publicación de este artículo. 


\section{REFERENCIAS BIBLIOGRÁFICAS}

Augé, M. (1988). Dios como objeto. Símbolos, cuerpos, materias, palabras. Barcelona: Gedisa.

Boletín Museo Nacional de Historia Natural de Chile (1957-1959). 1(XXVII).

Brugnoli, P., Jélvez, P. y Hoces de la Guardia, S. (2011). Colores: Un puente entre pasado y presente. Revista Diseña, 3. Recuperado de http://www.revistadisena.com/colores-un-puente-entre-pasado-y-presente/

Calancha, A. (1638). Chronica moralizada del orden de S. Agustín En el Perú, con sucesos exemplares vistos en esta Monarchia. Barcelona: JCBL.

Corcuera, R. (1987). Herencia textil andina. Buenos Aires: Impresores S.C.A.

Garcilaso de la Vega, Inga (1991). Comentarios reales de los incas. Lima: Fondo de Cultura Económica.

Mignone, P. (2015). Illas y Allicac. La Capacocha del Llullaillaco y los mecanismos de ascenso social de los «Inkas de privilegio». Boletín Museo Chileno de Arte Precolombino, 20(2), pp. 69-87.

Morssink, R. (1999). La plata en las culturas andinas. Chungará, 31(1), pp. 49-80.

Rostworowski, M. (2017). Los incas. Lima: Instituto de Estudios Andinos.

Rostworowski, M. (2005). Redes económicas del Estado inca: el ruego y la dádiva. Lima: Instituto de Estudios Andinos.

Siracusano, G. (2005). El poder de los colores. De lo material a lo simbólico en las prácticas culturales andinas. Siglos XV-XVII. Buenos Aires: Fondo de Cultura Económica. 